\title{
PADRONIZAÇÃO DO TESTE ELISA BASEADO EM ANTÍGENO CAPSULAR PURIFICADO DOS SOROTIPOS 3, 5 E 7 DE Actinobacillus pleuropneumoniae
}

\author{
STANDARIZATION OF ELISA TEST BASED ON PURIFIED CAPSULAR ANTIGEN \\ FROM SEROTYPES 3, 5 AND 7 OF Actinobacillus pleuropneumoniae
}

\author{
Valéria Dutra ${ }^{1}$ Itamar Piffer $^{2}$ Agueda Castagna de Vargas ${ }^{3}$ Antônio Guidoni ${ }^{2}$ Cátia Klein $^{4}$
}

\section{RESUMO}

\begin{abstract}
Foram padronizados testes de ELISA (Enzymelinked immunosorbent assay) baseados em antígeno capsular purificado de Actinobacillus pleuropneumoniae sorotipos 3, 5 e 7, prevalentes no Brasil. Para a padronização foram utilizadas amostras de soro provenientes de leitões inoculados com os três sorotipos do agente em estudo, dos quais se colheram amostras de sangue semanais, durante 15 semanas para estudo da dinâmica da síntese de anticorpos. O controle negativo dos testes constituiu-se de um mistura de 130 soros de animais livres de Actinobacillus pleuropneumoniae (App). Os antígenos também foram testados com amostras de soro de animais infectados com outros agentes causadores de doenças respiratórias e vacinados contra rinite atrófica. Os antígenos produzidos foram eficientes na detecção de animais infectados com App, permitindo determinar densidades óticas superiores à média dos soros controles negativos acrescida de quatro desvios-padrões. Os testes de ELISA para os sorotipos 3, 5 e 7 apresentaram especificidade de $100 \%$ e sensibilidade de 92, 88 e 90\%, respectivamente. Não ocorreram reações cruzadas com outros sorotipos, assim como com soros de animais inoculados com outros agentes causadores de problemas respiratórios. Os resultados foram analisados através da análise discriminante de ANDERSON (1958), utilizando-se o programa Statistical Analysis System. Concluiu-se que os antígenos testados são adequados para sorotipar animais que tenham sido submetidos ao screening através de um teste de ELISA polivalente baseado em LPS-LC.
\end{abstract}

Palavras-chave: Actinobacillus pleuropneumoniae, ELISA, antígeno capsular.

\section{SUMMARY}

Three ELISA (Enzime-linked immunosorbent assay) tests based on purified capsular antigen from serotypes 3, 5 and 7 of Actinobacillus pleuropneumoniae, prevalent in Brazil, were standardized. Serum samples, collected from piglets inoculated with these three serotypes, were used to standardize the test. In order to study the dynamic of antibody synthesis, weekly blood samples were collected from these piglets. A pool of 130 sera obtained from Actinobacillus pleuropneumoniae -free pigs was used as negative control for the tests. The antigens were also tested with serum samples from animals infected with other respiratory infectious agents and vaccinated against athrofic rinitis. The antigens were efficient in detecting animals infected with App. Optical densities above the average of the negative control sera plus four standard deviation were detected. ELISA tests to serotypes 3, 5 and 7 showed specificity of $100 \%$ and sensibility of 92,88 and $90 \%$, respectively. No cross reaction with other serotypes or with sera of animals inoculated with other respiratory pathogens was observed. The results were analyzed using the Statistical Analysis System program. Antigens tested were adequate for serotyping animals previously screened through a polyvalent LPS-LC ELISA test.

Key words: Actinobacillus pleuropneumoniae, ELISA, capsular antigen.

\section{INTRODUÇÃO}

Com a intensificação da produção de suínos no Brasil, os problemas sanitários têm sido uma preocupação constante de técnicos e produtores, tanto pela morte de animais e gastos com medicamentos, como pela redução nos índices produtivos. Um dos grandes problemas das criações suinícolas são as doenças respiratórias. Essas ocorrem mundialmente, sendo que as pneumonias são responsáveis pela perda de 2, 4 suínos, com peso de $95 \mathrm{~kg}$, para cada 100 animais abatidos no sul do Brasil (PIFFER et al., 1995).

\footnotetext{
${ }^{1}$ Médico Veterinário, MSc., Professor Assistente, Departamento de Clínica Médica Veterinária, Universidade Federal do Mato Grosso.

${ }^{2}$ Pesquisador Embrapa, CNPSA, Concórdia, SC.

${ }_{3}^{3}$ Médico Veterinário, MSc., Professor Assistente, Departamento de Medicina Veterinária Preventiva, Universidade Federal de Santa

Maria, 97105-900, Santa Maria, RS, E-mail: agueda @ ccr.ufsm.br (autor para correspondência).

${ }^{4}$ Bióloga, Embrapa-CNPSA-Concórdia, SC.
} 
O Actinobacillus pleuropneumoniae (App) é o agente etiológico primário da Pleuropneumonia Suína (PPS). Essa doença caracteriza-se por uma pneumonia necrohemorrágica, freqüentemente associada a uma pleurisia fibrinosa (PIFFER et al., 1987). O primeiro surto dessa doença foi descrito na Inglaterra (MATHEWS \& PATTISON, 1961), enquanto que no Brasil, a PPS foi diagnosticada pela primeira vez por LOCATELLI et al., (1981). A partir de então, vários surtos dessa doença foram diagnosticados no sul do Brasil, onde a suinocultura é praticada de forma intensiva (PIFFER $\boldsymbol{e t}$ $\boldsymbol{a l}$. , 1995). Atualmente, existem relatos da ocorrência da PPS em todos os países onde o sistema intensivo é adotado para produção de suínos (PIFFER et al., 1987).

Como fatores de virulência do App são reconhecidos: cápsula, endotoxina (JANSEN \& BERTRAM, 1986) e três citolisinas (LEENGOED \& DICKERSON, 1992; JANSEN et al., 1992). Baseados nas características dos polissacarídeos capsulares, foram descritos para o App 12 sorotipos (NICOLET, 1992; GUNNARSSON et al., 1977; NIELSEN, 1988) e sete antígenos somáticos (NAKAI et $\boldsymbol{a l}$., 1992). Os sorotipos 1, 9 e 11 apresentam o antígeno somático 01 ; os sorotipos 3,6 e 8 , o antígeno somático 03 e os sorotipos 4 e 7, o antígeno somático 04 (NAKAI $\boldsymbol{e t}$ al., 1992). Levantamentos realizados no Brasil identificaram os sorotipos 3,5 e 7 como prevalentes (PIFFER $\boldsymbol{e t}$ al., 1987). Essa diversidade no predomínio dos sorotipos reforça a necessidade de uma contínua sorotipagem dos App isolados nas regiões endêmicas para que testes sorológicos e vacinas sejam adequados.

A PPS é transmitida por aerossóis ou fômites, ocorrendo principalmente por via aerógena e através de contato direto entre os suínos mantidos na mesma baia ou em baias adjacentes (MORES $\boldsymbol{e t}$ al., 1984). Fatores ambientais, como mudanças bruscas de temperatura, alta umidade relativa do ar e transporte de animais, predispõem à aquisição e disseminação da infecção (ABASCAL et al., 1994). Os suínos portadores constituem a principal fonte da infecção. Mesmo nos rebanhos imunes, o App pode persistir, tanto no tecido pulmonar necrótico encapsulado, como nas amígdalas, independente do título de anticorpos (MORES et al., 1984).

A disponibilidade de testes sensíveis e específicos é essencial na determinação do status sanitário dos rebanhos. Esses testes são necessários, principalmente, para aqueles rebanhos responsáveis pelo melhoramento genético e multiplicação de animais melhorados. A contaminação desses rebanhos e a manutenção do comércio de reprodutores significam fontes permanentes de infecção para o rebanho nacional, principalmente quando estiverem presentes animais sadios, atuando como portadores de microrganismos patogênicos.

FENWICK (1992) conduziu uma comparação crítica entre os testes sorológicos para PPS. Dessa comparação, o teste de ELISA e o de neutralização das citolisinas foram os melhores, porém o último não foi eficiente para o sorotipo 7. Dentre os testes utilizados, o ELISA é considerado rápido e sensível, facilmente automatizado e tem a vantagem de apresentar poucos resultados falsos-positivos quando comparado a outros testes (FENWICK \& HENRY, 1994). Vários tipos de antígenos podem ser usados no teste ELISA, entre eles, o extrato salino fervido e centrifugado, o lipopolissacarídeo de cadeia longa (LPS-LC) e o polissacarídeo capsular (GOTTSCHALK et al., 1994).

O presente trabalho objetivou a produção e padronização de um teste de ELISA baseado em antígeno capsular purificado dos sorotipos 3, 5 e 7 de $\boldsymbol{A p p}$, para eliminar a possibilidade de ocorrência de reações cruzadas entre alguns sorotipos de Actinobacillus pleuropneumoniae, assim como com outros agentes patogênicos do aparelho respiratório dos suínos.

\section{MATERIAL E MÉTODOS}

No cultivo das cepas padrões dos três sorotipos para produção do antígeno, foi utilizado Columbia ágar ${ }^{\mathrm{a}}$ contendo $10 \mathrm{ug}$ de $\mathrm{NAD} / \mathrm{m} \ell$ de meio. Essas cepas foram cultivadas durante 24 horas a $37^{\circ} \mathrm{C}$. Após esse período, as colônias iridescentes foram selecionadas e repicadas. A partir desse crescimento, cada sorotipo foi cultivado em 3 litros de caldo Columbia ${ }^{\mathrm{b}}$ acrescido de $20 \mathrm{ug}$ de NAD/m $\ell$ de meio e incubado por 10 horas a $37^{\circ} \mathrm{C}$. Esse material foi centrifugado a $10.000 \mathrm{x}$ g por 10 minutos e o sobrenadante foi precipitado com $1,825 \mathrm{~g} / \ell$ de hexadecyltrimethylammonium bromide (CETAVLON) ${ }^{\mathrm{c}}$. $\mathrm{O}$ precipitado contendo a cápsula foi recolhido através de centrifugação a 10.000 x g durante 30 minutos a $4^{0} \mathrm{C}$ e solubilizado com $\mathrm{NaCl}$ a $0,4 \mathrm{M}$. Após uma nova centrifugação a 10.000 x g durante 30 minutos a $4^{0} \mathrm{C}$, foi recolhido o material não solubilizado. $\mathrm{O}$ material em suspensão contendo a cápsula foi precipitado com etanol (2,5 vezes o volume). Esse material foi ressuspenso em água destilada e sofreu em média três a quatro extrações fenólicas. A solução aquosa da extração fenólica, contendo a cápsula, foi dialisada durante 3 dias, com 3 trocas diárias de água, até que o odor do fenol desaparecesse. Ao volume obtido foi adicionado $\mathrm{NaCl} 0,1 \mathrm{M}$ e 
novamente 2,5 vezes o volume de etanol. Esse material foi ultracentrifugado a $105.000 \mathrm{x}$ g por 4 horas a $4^{0} \mathrm{C}$ (INZANA, 1987).

Para cada sorotipo foi padronizado um teste de ELISA, no qual todos os componentes do ensaio foram testados no mesmo instante e sob as mesmas condições. A padronização dos reagentes e a condução dos testes de ELISA foram realizadas em placas de poliestireno de 96 cavidades. Os antígenos foram submetidos à mensuração protéica através do método de LOWRY et al. (1951), modificado por MARKWELL et al. (1978), usando-se albumina de soro bovino como padrão (Biorad). Os carboidratos foram determinados através do método de DUBOIS et al. (1956). Os dados das leituras espectrofotométricas foram transferidos ao computador para o programa KELA e os mesmos foram processados e corrigidos para variações diárias de acordo com JACOBSON \& DOWNING (1991). Na padronização do teste, levou-se em consideração a presença de reações inespecíficas, testando-se a mesma amostra de soro na presença e na ausência do antígeno, simultaneamente na mesma placa. Os antígenos diluídos na sua dose de reatividade ótima pré-determinada, em tampão carbonato-bicarbonato $0,05 \mathrm{M} \mathrm{pH}$ 9,6 foram adicionados na quantidade de 100ul a cada cavidade das microplacas, sendo as mesmas incubadas durante uma noite, a $37^{\circ} \mathrm{C}$, em câmara úmida. A lavagem das placas foi feita com PBS $0,15 \mathrm{M}$ pH 7,4 contendo $0,05 \%$ de Tween $20^{\mathrm{d}}$. Como solução bloqueadora foram testados albumina e leite em pó desnatado, diluídos na solução de PBS $0,15 \mathrm{M}$ pH 7,4 nas concentrações de 1,2 e $3 \%$. O conjugado antiIgG de suíno utilizado foi o da marca Sigma, assim como o cromógeno (ABTS) ${ }^{\mathrm{e}}$. O tempo de incubação para cada etapa da reação foi de 60 minutos, com exceção da incubação do revelador que foi de trinta minutos. A leitura foi feita com comprimento de onda de $405 \mathrm{~nm}$. As concentrações dos reativos escolhidas foram as que possibilitaram separar a população positiva da população negativa, resultando em leitura de DO ao redor de 1,0 com os soros positivos. Após a padronização dos reativos, um conjunto de soros considerados negativos para o App e também um conjunto de soros considerados positivos foram submetidos ao teste.

Os antígenos dos sorotipos 3, 5 e 7 foram testados no teste de ELISA com soros de animais positivos para Haemophillus parasuis, Actinobacillus suis, Mycoplasma hyopneumoniae, Mycoplasma floculare, Bordetella bronchiseptica, Pasteurella multocida e todos os sorotipos de App para observação de possíveis reações cruzadas.

Os controles negativos foram constituídos por um "pool" de 130 soros de suínos livres de in- fecção por App. Os controles positivos foram obtidos de animais inoculados com os sorotipos 3, 5 e 7 e que apresentaram soroconversão, ou seja, valores iguais ou superiores à média dos soros controles negativos acrescida de quatro desvios-padrões. Com as densidades óticas dos soros ajustadas, foram determinadas as equações discriminantes de ANDERSON (1958), para as populações positivas e negativas. Após a classificação dos soros pelas funções, realizou-se análise de concordância entre os resultados (positivos e negativos) e os dados da função discriminante. Cada teste de ELISA foi comparado quanto à distância generalizada de Mahalanobis (D2), coeficiente de determinação (R2), teste $\mathrm{F}$, coeficiente global do teste (CG), sensibilidade e especificidade. A análise estatística pertence ao procedimento DISCRIM do SAS (1985).

\section{RESULTADOS E DISCUSSÃO}

Os resultados mostraram que, apesar da produção do antígeno capsular purificado ser mais trabalhosa em relação a outros antígenos baseados em LPS, os antígenos foram satisfatórios na detecção de anticorpos nos animais inoculados com os sorotipos 3, 5 e 7, classificando como negativos os animais inoculados com os demais sorotipos.

Os antígenos dos sorotipos 3, 5 e 7 de App foram padronizados nas seguintes diluições: sorotipo 3 a 1/64, sorotipos 5 e 7 a 1/256. Os resultados encontrados na análise de proteínas e carboidratos nas soluções de trabalho foram para o sorotipo $3 \mathrm{em}$ torno de $30 \mathrm{ug}$ de proteína/m $\ell$ de antígeno e 90ug de carboidrato/m $\ell$ de antígeno. O sorotipo 5 apresentou 20ug de proteína/m $\ell$ e $90 \mathrm{ug} / \mathrm{m} \ell$ de carboidrato/m $\ell$ de antígeno. $\mathrm{O}$ sorotipo 7 apresentou 20ug e $45 \mathrm{ug} / \mathrm{m} \ell$ de antígeno para proteínas e carboidratos, respectivamente. Os soros apresentaram melhores resultados quando diluídos a 1/100 e o conjugado a $1 / 3000$ com os três sorotipos. O melhor bloqueador foi o leite em pó desnatado a $3 \%$.

RADACOVICCI et al. (1992) compararam vários tipos de antígenos quanto à quantidade de proteínas, entre eles, o extrato cru, extrato cru dialisado e ainda as partes aquosa e fenólica, resultantes da extração fenólica do antígeno, a fim de separar os diferentes componentes imunogênicos. Os mesmos observaram que a extração fenólica reduziu consideravelmente a quantidade de proteínas no antígeno. Dessas diferentes frações, os autores mediram proteínas e carboidratos, e observaram que esses componentes diminuem proporcionalmente a pureza do antígeno. No extrato cru, foram encontrados valores de 2,12mg de proteína e 2,06mg de carboidrato/ml 
de antígeno. Na fase aquosa da extração fenólica, que foi a fração mais purificada no estudo, encontraram-se valores de $0,08 \mathrm{mg}$ de proteína e $0,20 \mathrm{mg}$ de carboidrato/m $\ell$ de antígeno. Os mesmos concluíram que quanto mais intensa é a purificação, maior é a capacidade de promover interações específicas com as imunoglobulinas, pois quanto maior a diversidade de proteínas, maior será a probabilidade de ocorrência de reações cruzadas. Portanto, em preparações mais purificadas, como no caso do antígeno capsular, as reações cruzadas tendem a diminuir. BOSSÉ et al. (1992) também observaram que as proteínas contaminantes da solução de trabalho nos testes de ELISA, baseados em cápsula e LPS, não comprometeram a eficiência da especificidade desses testes.

Com os resultados obtidos nos testes de ELISA baseados em antígeno capsular purificado dos sorotipos 3, 5 e 7 , observou-se que não ocorreram reações cruzadas, quando testados animais inoculados com os sorotipos 1, 2, 4, 6, 8, 9, 11 e 12, bem como quando foram testados soros de animais inoculados e vacinados com os principais agentes que infectam o sistema respiratório dos suínos (Pasteurella multocida e Bordetella bronchiseptica, Actinobacillus suis, Haemophilus parasuis, Mycoplasma hyopneumoniae $e$ Mycoplasma floculare), indicando que os níveis protéicos que contaminam os antígenos não estão interferindo na especificidade do teste. Ao utilizar o antígeno capsular, alguns autores têm registrado reações cruzadas entre alguns sorotipos do App (1, 2, 3 e 5) e alguns do Actinobacillus suis, em outros testes sorológicos (BOSSÉ et al., 1992; GOTTSCHALK et al., 1994). Isso pode estar associado ao tipo dos sorotipos envolvidos. No presente trabalho, os testes de ELISA não apresentaram reações cruzadas quando testados com amostras de soros positivos para os diferentes microrganismos que afetam o sistema respiratório dos suínos. Através da observação de sinais reacionais inespecíficos, os resultados mostraram que ao se utilizar o antígeno capsular não houve diferenças quando as amostras foram testadas somente na presença ou na presença e ausência do antígeno simultaneamente na placa. BROES et al. (1996) citam que esse efeito pode ser originário de diferentes fenômenos, tais como uma adsorção inespecífica às placas, de imunoglobulinas presentes nas amostras testadas e à presença de anticorpos reagindo cruzada- mente com antígenos adsorvidos às placas, principalmente no caso de animais mais velhos. Como no presente trabalho não se observaram diferenças, optou-se pelo teste das amostras de soro apenas na presença do antígeno, resultando na redução dos custos do teste e da mão-de-obra.

A tabela 1 fornece as estimativas das equações discriminantes de ANDERSON para as populações negativa e positiva dos três testes estudados, bem como a distância generalizada de Mahalanobis (D2) entre essas populações, o teste F, o coeficiente de determinação (R2), a Sensibilidade (S), a Especificidade (E) e o coeficiente global do teste (CG). A sensibilidade e especificidade do teste foram calculados levando em conta a análise de concordância entre o status dos animais e a função discriminante de ANDERSON. O coeficiente global do teste representa a sua eficiência, ou seja, a proporção de animais com status positivo e negativo que a função classificou corretamente.

Através da observação da dinâmica da síntese de anticorpos, o teste detectou resposta sorológica ao sorotipo 3 na terceira semana após a infecção, enquanto que os sorotipos 5 e 7 foram detectados na primeira semana. MACHADO $\boldsymbol{e t}$ al. (1997) observaram a dinâmica da síntese de anticorpos nesses mesmos animais através do teste ELISA baseado em LPS-LC e concluíram que os animais inoculados com o sorotipo 3 apresentaram soroconversão entre a segunda e quarta semana após a inoculação, enquanto que com os sorotipos 5 e 7, ocorreu entre a primeira e segunda semana após a exposição ao antígeno. Nos três casos, os títulos de anticorpos permaneceram até o final do experimento (15 semanas). Rogers $\boldsymbol{e t}$ al., apud ROHRBACH $\boldsymbol{e t}$ al. (1993), comentam sobre as diferenças significativas na virulência dos doze sorotipos, citando os sorotipos 1 e 5 como mais patogênicos, enquanto o soroti-

Tabela 1 - Estimativa dos parâmetros das funções discriminantes de ANDERSON do tipo $\mathrm{Z}=\mathrm{a}+\mathrm{b} \mathrm{X}$ densidade ótica ajustada, para os valores de ELISA referentes às populações negativa e positiva, a distância generalizada de Mahalanobis (D2), coeficiente de determinação (R2), teste F e coeficiente global do teste (CG) (eficiência dos testes), Sensibilidade (S) e Especificidade (E) dos testes.

\begin{tabular}{|c|c|c|c|c|c|c|c|c|c|}
\hline TESTEa & NEGATIVOS & POSI & TIVOS & D2 & $\mathrm{R} 2$ & $\mathrm{~F}$ & $\mathrm{CG}$ & S & $\mathrm{E}$ \\
\hline A & B & $\mathrm{b}$ & $(\%)$ & $(\%)$ & & $(\%)$ & $(\%)$ & $(\%)$ & \\
\hline 3 & $0,224353,17438$ & 8,26196 & 19,26357 & 11,52 & 68,95 & 428 & 97,94 & 92 & 100 \\
\hline 5 & $0,825899,73838$ & 21,1339 & 49,26253 & 27,21 & 79,86 & 593 & 98,13 & 88 & 100 \\
\hline 7 & $2,4149618,9078$ & 19,95579 & 54,35271 & 16,97 & 76,75 & 640 & 97,44 & 90 & 100 \\
\hline
\end{tabular}

$=$ sorotipo utilizado no teste. 
po 3 é considerado menos virulento (NICOLET, 1992). Os animais inoculados e testados com ELISA capsular também mantiveram os títulos elevados até o final do experimento. Os sorotipos 5 e 7 apresentaram uma soroconversão mais precoce, comparado ao sorotipo 3. Isso também pode ser associado à referida variação na virulência entre os sorotipos (NICOLET, 1992; ROHRBACH et al., 1993). BOSSÉ et al. (1992) conduziram um experimento expondo os animais ao sorotipo 1 de App através de aerossóis e observando a resposta imune sistêmica e local através de ELISA baseado em cápsula e LPSLC. Esses autores não observaram diferenças na imunogenicidade dos antígenos utilizados, sendo que ambos induziram resposta aos 7 dias após a inoculação, indicando não haver uma variação muito grande no tempo de resposta imunológica entre o antígeno capsular e o LPS-LC.

A partir da padronização do teste ELISA baseado em cápsula, as amostras de soro a serem testadas no diagnóstico da PPS poderiam ser submetidas ao screening através do ELISA baseado em LPS-LC, que possui sensibilidade de mais de 95\%; numa segunda etapa, algumas amostras que fossem altamente positivas, seriam testadas com o ELISA baseado em antígenos capsulares dos sorotipos contidos nos testes que possuem $100 \%$ de especificidade. Isso possibilitaria a identificação do sorotipo presente no rebanho, com um custo razoável.

\section{CONCLUSÕES}

Os antígenos capsulares dos sorotipos 3, 5 e 7 de Actinobacillus pleuropneumoniae (App) utilizados no teste ELISA detectam soroconversão em animais infectados experimentalmente. As amostras de soro de animais infectados com Haemophilus parasuis, Mycoplasma hyopneumoniae, Mycoplasma floculare, Actinobacillus suis e de animais vacinados com Bordetella bronchiseptica e Pasteurella multocida não apresentam reações cruzadas com os antígenos capsulares. Os antígenos estudados não reagem com amostras de animais inoculados com sorotipos que possuem lipopolissacarídeos homólogos e nem com os demais sorotipos estudados, reagindo apenas com amostras de soro positivas específicas dos sorotipos 3, 5 e 7 de Actinobacillus pleuropneumoniae.

\section{FONTE DE AQUISIÇÃO}

a - Sigma Chemical CO - St Louis, USA.

b - Sigma Chemical CO - St Louis, USA.

c - Interprise Instrumentos Analíticos, São Paulo-SP.

d - Sigma Chemical CO - St Louis, USA.

e - Sigma Chemical CO - St Louis, USA.

\section{REFERÊNCIAS BIBLIOGRÁFICAS}

ABASCAL, E.N.,TENORIO, V.R., SERRANO, J.J., et al., Secreted proteases from Actinobacillus pleuropneumoniae serotype 1 degraded porcine gelatin, hemoglobin and immunoglobulin A. Canadian Journal of Veterinary Research, v.58, n.2, p.83-86, 1994.

ANDERSON, T.W. Classification of observations. In: ANDERSON, T. W. Introduction to multivariate statistical analysis. New York : John Wiley, 1958. p.126-152.

BOSSÉ, J.T., FRIENDSHIP, R., ROSENDAL, S. Evaluation of a pooled-antigen ELISA for serodiagnosis of Actinobacillus pleuropneumoniae serotypes 1,5 and 7 Infections. In: INTERNATIONAL PIG VETERINARY SOCIETY, 12, 1992, The Hague. Proceedings... The Hague : International Pig Veterinary Society, 1992. 671p. p.220.

BROES, A., GOTTSCHALK, M., BOUTIN, R., et $\boldsymbol{a l}$. Actinobacillus pleuropneumoniae serotype 1 ELISA serology: influence of age on background reactivity. In: INTERMATIONAL PIG VETERINARY SOCIETY, 14, 1996, Bologna. Proceedings... Bologna : International Pig Veterinary Society, 1996. P767p. p.202.

DUBOIS, M., GILlES, K.A., HAMILTON, J.K., $\boldsymbol{e} \boldsymbol{t} \boldsymbol{a l}$, Colorimetric method for determination of sugars and related substances. Analisys Chemical, v.28, p.350-356, 1956.

FENWICK, B. Critical comparasion of the serologic tests used to diagnose porcine pleuropneumoniae. In: INTERNATIONAL PIG VETERINARY SOCIETY, 12, 1992, The Hague. Proceedings... The Hague : International Pig Veterinary Society, 1992. 671p. p.226

FENWICK, B., HENRY, S. Porcine Pleuropneumonia. Journal of the American Veterinary Medical Association, v.204, n.9, p.1334-1340, 1994.

GOTTSCHALK, M., ALTMAN, E., CHARLAND, N., $\boldsymbol{e}$ t $\boldsymbol{a}$. Evaluation of a saline boiled extract, capsular polysaccharides and long-chain lipopolysaccharides of Actinobacillus pleuropneumoniae serotype 1 as antigens for the serodiagnosis of swine pleuroneumonia. Veterinary Microbiology, n.99, p.1-15, 1994

GUNNARSSON, A., BIBERSTEIN, E.L., HURVELL, B Serologic studies on porcine strains of Haemophilus parahaemolyticus (pleuropneumoniae): aglutination reactions. American Journal of Veterinary Research, v.38, p.1111-1114, 1977.

INZANA,T.J. Purification and partial characterization of the capsular polymer of Haemophilus pleuropneumoniae serotype 5. Infection and Immunity, v.55, n.7 p.1573-1587, 1987.

JACOBSON, R.H., DOWNING, D.R. KELA Acquisition, management and analysis of ELISA data. Ithaca : College of Veterinary Medicine, Diagnostic Laboratory, Cornell University, 1991.71p.

JANSEN, A.E., BERTRAM, T.A. Morphological and biochemical comparasion of virulent and avirulent isolates of Haemophilus pleuropneumoniae serotype 5. Infection and Immunity, v.51, n.2, p.419-424, 1986. 
JANSEN, R., BRIAIRE, J., KAMP, E., et $\boldsymbol{a l}$., The cytolysin genes of Actinobacillus pleuropneumoniae. In: INTERNATIONAL PIG VETERINARY SOCIETY, 12, 1992, The Hague. Proceedings... The Hague : International Pig Veterinary Society, 1992. 671p. p.219.

LEENGOED, VAN L.A., DICKERSON, H.W. Influence of calcium secretion and activity of the cytolysins of Actinobacillus pleuropneumoniae. Infection and Immunity, v.60, n.2, p.353-359, 1992.

LOCATELli, J.C., MACHADO, A., SÁ e SILVA A., et al. Ocorrência da pleuropneumonia suína causada pelo Haemophilus pleuropneumoniae In: CONGRESSO ESTADUAL DE MEDICINA VETERINÁRIA, 6, 1981, Gramado. Anais... Gramado : Sociedade Veterinária do Rio Grande do Sul e Associação de Clínicos Veterinários de Pequenos Animais, 1981. 126p. p.36-37.

LOWRY, O.H., ROSEBROUGH, N.J., FARR, A.L., et al. Protein measurement with the folin phenol reagent. Journal Biological Chemistry, v.193, p.265-275, 1951.

MACHADO, H.P., PIFFER, I.A., TURNES, G. Persistência de anticorpos contra os sorotipos prevalentes de Actinobacillus pleuropneumoniae (App) detectados por testes de ELISA. In: CONGRESSO BRASILEIRO DE VETERINÁRIOS ESPECIALISTAS EM SUÍNOS, 8, 1997, Foz do Iguaçú. Anais... Foz do Iguaçú : Associação Brasileira de Veterinários Especialistas em Suínos, 1997. 463p. p.187.

MARKWELL, M.A.K., HASS, S.M., BIEBER, L.L., $\boldsymbol{e}$ t al. A modification of the Lowry procediment to simplify protein determination in the membran and lipoprotein samples. Analyses Biochemicals, v. 87, p. 206-210, 1978.

MATHEWS, P.R.J., PATTISON, I.H. The identification of a Haemophillus-like organism associated with pneumonia and pleurisy in the pig. Journal of Comparative Pathology, v.51, p.44-52, 1961.

MORES, N., SOUZA, J.C.A, NOGUEIRA, R.H.G. Estudo experimental da pleuropneumonia suína causada por Haemo- philus pleuropneumoniae (Hpp): patogenicidade e evolução das lesões anatomo-patológicas. Arquivo Brasileiro de Medicina Veterinária e Zootecnia, Belo Horizonte, v.36, n.6, p.679-693, 1984.

NAKAI, T., ONO, K., IKE, K., et al. Serotyping of Actinobacillus pleuropneumoniae Strains by Useof Purified Capsular Polysacchharide or Lipopolysaccharide In: INTERNATIONAL PIG VETERINARY SOCIETY, 12, 1992, The Hague. Proceedings... The Hague : International Pig Veterinary Society, 1992.671p. p.186.

NICOLET, J. Actinobacillus pleuropneumoniae In: LEMAN, A.D. Diseases of swine. Iowa : Iowa State University, 1992. p.401-413.

NIELSEN, R. Seroepidemiology of Actinobacillus pleuropneumoniae. Canadian Veterinary Journal, Ottawa, v.29, p.580-582, 1988.

PIFFER, I.A., BRITO, M.A.V.P., BRITO, J.R.F., et al. Sorotipos de Haemophilus (Actinobacillus) pleuropneumoniae isolados de suínos no Brasil. Pesquisa Veterinária Brasileira, Rio de Janeiro, v.7, p.79-83, 1987.

PIFFER, I. Doenças respiratórias na produção de suínos: A relevância do problema. In: CONGRESSO BRASILEIRO DE VETERINÁRIOS ESPECIALISTAS EM SUÍNOS, 7, 1995, Blumenau. Anais... Blumenau : Associação Brasileira de Veterinários Especialistas em Suínos, 1995. 240p. p.31.

RADACOVICCI, S., LARIVIERE, S., DUBREUIL, D. Biochemical characterization of an antigenic saline extract of Actinobacillus pleuropneumoniae serotype 5 and identification of a serotype specific antigen for ELISA serodiagnosis. Veterinary Microbiology, v.30, p.369-385, 1992.

ROHRBACH, B.W., HALL, R.F., HITCHCOCK, J.P. Effect of subclinical infection with Actinobacillus pleuropneumoniae in commingled feeder swine. Journal of the American Veterinary Medical Association, v.202, n.7, p.1095-1098, 1993. 